\title{
Política E "VIOLÊNCIA CRIMINAL" NO BRASIL: A REAPROPRIAÇÃo DE IMAGINÁRIOS Plebeus PELO PRIMEIRo CoMANDO DA CAPITAL
}

\author{
Benoit Décary-Secours ${ }^{1}$
}

\begin{abstract}
Resumo
Apoiado nas teorias da plebe, este artigo propõe uma contribuição teórica para a análise política da "violência criminal" no Brasil, a partir dos imaginários transmitidos pelo discurso do Primeiro Comando da Capital (PCC). Nós sugerimos a existência de um "PCC-plebeu", que, ao contrário da interpretação dominante em termos de "PCC-crime organizado", permite abordá-lo como conjunto singular de enunciados políticos, que transcendem a organização criminosa e fornecem uma melhor compreensão da politização e propagação dos imaginários criminais no contexto democrático.
\end{abstract}

Palavras-chave: violência criminal, Primeiro Comando da Capital (PCC), plebe, imaginário, Brasil.

\section{Resumen}

Con el apoyo de las teorías de la plebeya, en este artículo se propone una contribución teórica al análisis político de la "violencia criminal" en Brasil, a partir del discurso imaginario transmitido por el Primer Comando de la Capital (PCC). Se sugiere la existencia de un "PCC-plebeyo", que, a diferencia de la interpretación dominante en términos de "PCC crimen organizado", permite el enfoque como un único conjunto de propuestas políticas que trascienden la organización criminal y proporcionar una mejor comprensión la politización y la propagación de un imaginario criminal en un contexto democrático.

Palabras clave: violencia criminal, Primer Comando de la Capital (PCC), chusma, imaginario, Brasil.

\begin{abstract}
Following the theories of the plebs, this article proposes a theoretical contribution to the political analysis of "criminal violence" in Brazil, from the imaginary speech transmitted by the First Command of the Capital (PCC). We suggest the existence of a "PCC--plebeian", which, unlike the dominant interpretation in terms of "PCC - organized crime", lets approach it as a unique set of political propositions that transcend the criminal organization and provide a better understanding of politicization and propagation of criminal imaginary in a democratic context.
\end{abstract}

Keywords: criminal violence, First Command of the Capital (PCC), plebeians, imaginary, Brazil.

\section{INTRODUÇÃO}

Se um consenso geral estabelece que a violência política é uma das características essenciais das ditaduras militares latino-americanas dos anos 1960 e 1970, pesquisadores encontraram com assombro a intensificação de certas formas de violência juntamente à normalização das instituições democráticas no continente (ZALUAR, 2007; PERALVA,

\footnotetext{
1 Doutorando em Ciência política na Universidade do Ottawa (Canadá) e pesquisador no Groupe de recherche sur les imaginaires politiques en Amérique latine (GRIPAL).
} 
2001; CALDEIRA, 2000; KRUIJT e KOONINGS, 1999). No Brasil, esta "nova" forma de violência chamada de "criminal" se expressa essencialmente através das taxas de homicídios e tornou-se uma questão prioritária de Segurança Pública, associada a determinadas áreas sociais e geográficas: as periferias e as prisões. Um discurso securitário de "despolitização" da violência ergue-se a partir da criação de uma equivalência entre "violência" e "crime", retraindo o aspecto político relacionado à dinâmica da violência e do crime. Contra a ideia de que a "violência" é apenas uma questão de Segurança Pública, este artigo tem como objetivo levar a sério o imaginário político transmitido no discurso do Primeiro Comando da Capital (PCC) para fornecer uma melhor compreensão do seu enraízamento em áreas pauperizadas. A partir do lema "Paz, Justiça, Liberdade e Igualdade", sugerimos que o Partido pode ser analisado essencialmente como um conjunto singular de enunciados ${ }^{2}$ articulados em torno de uma reapropriação de imaginários plebeus. Se esses imaginários se referem a uma memória das lutas políticas das categorias sociais marginalizadas, eles não são, porém, imunes à naturalização de uma ordem política totalitária. Esta tensão atravessa a dinâmica política do PCC e questiona as categorias habituais da análise política da violência criminal na América Latina.

Em primeiro lugar, este artigo irá proceder a uma exposição das principais teses que circulam na literatura da ciência política e sociológica sobre a questão da violência e do PCC destacando seus limites. Em seguida, propomos o conceito de imaginários plebeus e sua articulação histórica com a política como elemento essencial para uma análise política da experiência do PCC. A partir de um corpus discursivo, será demonstrado a centralidade de imaginários igualitários e emancipatórios no PCC, mas também a reintrodução paradoxal de uma nova ordem unitária e totalitária nos espaços prisionais e pauperizados.

\section{LITERATURA SOBRE O PCC}

\subsection{Entre o crime organizado e desejos de emancipação}

O PCC nasce no início da década de 1990, no âmbito carcerário paulista. Embora existam várias versões narrativas sobre a sua criação, a que domina estabelece o surgimento do PCC no dia 31 de agosto de 1993, em uma das instituições carcerárias mais rígidas do país: o

\footnotetext{
2 Um corpus discursivo sobre esse coletivo é formado, gradativamente, ao longo deste artigo, a partir da narrativa encontrado no depoimento de Marcola (apontado pela Segurança publica como líder do PCC) sobre nascimento do PCC, as alterações no lema do coletivo e as narrativas de detentos recolhidas a partir de uma documentação e monografia etnográficas. A abordagem do PCC como conjunto singular de enunciados é sugerida por Adalton Marques em entrevista com Bruno Manso (MANSO, 2009).
} 
Anexo da Casa de Custódia e Tratamento de Taubaté. Enquanto sua presença é hoje quase hegemônica nas prisões paulistas ${ }^{3}$, um número crescente de estudos também mostra a sua presença nas periferias de São Paulo (BIONDI, 2010; NUNES DIAS, 2013; FELTRAN, 2008; GODÓI, 2010; MARQUES, 2009; TEIXEIRA, 2009; 2012). Hoje, o PCC se adiciona à cadeia de equivalência criada entre "violência" e "crime" no Brasil e investe um espaço midiático e securitário em expansão (NUNES DIAS, 2013; ADORNO, e SALLA, 2007). No seio deste discurso securitário, a imagem do PCC é, contudo, construída por duas perspectivas bastante diferentes e até opostas. A primeira interpreta o PCC a partir do modelo clássico do "crime organizado". A segunda enfatiza os aspectos reivindicativos que estruturam a experiência do PCC e ultrapassam o seu universo exclusivamente "criminoso". Enquanto esta tensão na literatura aumenta a complexidade do fenômeno da violência criminal no Brasil, ela também reflete uma parte da realidade paradoxal que atravessa hoje a experiência política que caracteriza o PCC (BIONDI, 2010).

A perspectiva que domina o discurso midiático e político, mas também acadêmico (BOSI, 2007), aborda o PCC em uma ótica exclusivamente "criminal" e securitária. No início de 2000, surgiram dois eventos singulares atribuídos ao PCC pelas autoridades, constituindo-o como inimigo público número um. O primeiro está vinculado à megarebelião ocorrida em fevereiro de 2001 no sistema prisional paulista. Foi então que as autoridades reconheceram oficialmente no PCC uma entidade pertencente ao "crime organizado" (SOUZA, 2007): organização fortemente hierarquizada, motivada essencialmente pelo poder e pelo lucro e representando um sério enfrentamento ao "monopólio da violência física legítima" do Estado (MINGARDI, 2007: ADORNO e SALLA, 2007). Em seguida, se o PCC parecia estar limitado ao espaço da prisão, o evento nacionalmente conhecido como "ataques de maio de 2006" (ADORNO e SALLA, 2007), em que ataques coordenados em todas as periferias de São Paulo somaram-se a rebeliões em mais de oitenta prisões, é atribuído ao PCC e expôs publicamente a facção como um dos principais problemas na área da Segurança Pública paulista. Entre 12 e 20 de maio de 2006, 439 mortes por armas de fogo no Estado de São Paulo foram atribuídas ao crime organizado. A polícia responde a esses ataques de acordo com uma lógica de guerra: 493 homicídios cometidos por policiais nas periferias em uma semana e mais quinhentos outros

\footnotetext{
3 O Estado de São Paulo tem atualmente 147 unidades prisionais articuladas à Secretaria da Administração Penitenciária (SAP), representando um pouco mais de 150 mil detentos. A presença do PCC nas unidades prisionais não é oficialmente confirmado pelo Governo do Estado de São Paulo. A avaliação do controle de 90\% das unidades prisionais do estado pelo PCC é o resultado de uma estimativa feita por prisioneiros, exreclusos, visitantes, pesquisadores, jornalistas e advogados. Ver Nunes Dias (2011).
} 
assassinatos nas três semanas seguintes. Do ponto de vista do "crime organizado", as autoridades podem definir o PCC como sendo composto de 11.400 membros presentes em 22 estados brasileiros, no Paraguai e na Bolívia - incluindo mais de 7.800 em São Paulo - e dos seus $\mathrm{R} \$ 120$ milhões gerados anualmente no tráfico, pagamento de parcelas e sorteio de rifas. O diagnóstico das autoridades e dos acadêmicos que adotam o ponto de vista do "PCC-crime organizado" é o seguinte: estamos diante uma criminalidade organizada que faz um "apelo à violência desmedida, sem economia de mortos e de meios capazes de aterrorizar a sociedade [e não] diante de coletivos populares organizados que lutam contra as injustiças e as desigualdades sociais e pela afirmação e conquista de direitos" (ADORNO e SALLA, 2007).

No entanto, frente a esse discurso securitário reduzindo o PCC à uma experiência exclusivamente criminosa, pouco espaço midiático está disponível para falar das demandas dos prisioneiros, do descumprimento da Lei de Execuções Penais pelo próprio Estado mediante procedimentos inconstitucionais como o Regime Disciplinar Diferenciado (TEIXEIRA, 2009) ou da prática regular de maus tratos e tortura denunciadas por movimentos em defesa dos Direitos Humanos (ANISTIA INTERNACIONAL, 2011). Sem ignorar o aspecto criminoso e violento que caracteriza o PCC, a segunda perspectiva analítica incide especificamente sobre a existência de um conjunto singular de enunciados e experiências que moldam o PCC, referindo-se à opressão, à luta pela liberdade, a um ideal de emancipação, à paz e a justiça e ultrapassam o seu componente "criminoso" (ALVAREZ, SALLA e NUNES DIAS, 2013; FELTRAN, 2013; 2010; 2008; MARQUES, 2010; 2009; BIONDI, 2010). Sem estabelecer uma lista exaustiva de tais experiências retraídas pela perspectiva securitária, algumas delas, por exemplo, referem-se à versão narrativa dominante sobre a fundação do Partido como ato de autodefesa contra as injustiças diárias vivenciadas dentro da prisão (BARROS, 2006), ao fato de que o Comando reivindica lutar contra a opressão da sociedade e pela paz entre os "ladrões", à criação de uma língua vernacular (BIONDI, 2010; MARQUES, 2009), ao recuso da hierarquia e à verificação da igualdade, à recente adição da "igualdade" ao seu lema "Paz, Justiça, Liberdade", etc.

O objetivo, obviamente, não é a procura de uma legitimação das atividades criminosas do PCC, mas sim, tal como proposto pela antropóloga Karina Biondi, "levar a sério" o que pensam e dizem as pessoas que decidimos estudar, sobretudo, quando estão associadas à práticas criminosas (BIONDI, 2010). A partir da ilustração de enunciadoschaves do PCC, este artigo fornece essencialmente uma contribuição teórica para o estudo 
da dinâmica da violência no Brasil contemporâneo. Como sugerido por Adalton Marques (MANSO, 2009), o PCC pode e deve ser estudado como um conjunto singular de enunciados que circulam no âmbito carcerário, mas também nas periferias e espaços que não estão sob o controle do Partido. O objetivo prosseguido por este artigo é de circunscrever nesses enunciados a reapropriação de imaginários plebeus, se inscrevendo numa memória das lutas populares pela liberdade e igualdade dos setores marginalizados. Porém, veremos que estes imaginários da emancipação não excluem a possibilidade de um retorno à naturalização de uma nova ordem totalitária e desigual. Enquanto alguns têm descrito esta tensão em termos de "paradoxo" oriundo da justaposição de uma "política da imanência" à uma de "transcendência" (BIONDI, 2010), nosso propósito é o de uma consideração genealógica, uma interrogação sobre o enraizamento deste "paradoxo" no imaginário político dos espaços marginalizados da metrópole. Argumentamos que essa tensão entre o desejo de emancipação e a naturalização de uma ordem transcendente de dominação é contida numa experiência política singular: a da plebe.

\section{A POLÍTICA DOS IMAGINÁRIOS PLEBEUS}

A "plebe" refere-se tanto a uma tradição do pensamento filosófico, partindo de Maquiavel a Rancière, atravessando Montesquieu, Ballanche ou Foucault, como a um modo de subjetivação política da dissensão, recorrente na história ocidental (BREAUGH, 2007), mas que também atravessa as recentes revoltas populares na América Latina (CORTEN, PENAFIEL e HUART, 2012). Sem ser categoria identitária, nem movimento social organizado, a plebe é abarcada pelo tumulto e a desordem. Frequentemente taxada de violenta pela ordem política estabelecida, a plebe destaca uma situação inaceitável enquanto desconfiando da representação e sem propor ordem alguma ou projeto político alternativo. No entanto, a plebe não é menos política. Antes de ser uma categoria sociológica, a plebe refere-se à um pensamento filosófico sobre um determinado tipo de expressão política. Se, da perspectiva de Lefort, leitor de Maquiavel, toda ordem política distribui desigualmente a capacidade de participar plenamente das decisões coletivas com base numa divisão social entre os "grandes" e o "povo" (LEFORT, 1972), a plebe perturba essa distribuição habitual do direito à fala (RANCIÈRE, 1995). A plebe concorda com o surgimento efêmero de um sujeito político baseado na revelação do seu estatuto infrapolítico. Assim sendo, a plebe baseia-se numa antinomia abrangida no imaginário que, seguindo Castoriadis, "pressupõe a 
capacidade de ver em algo o que não seja, de vê-la outra do que esteja ${ }^{4 "}$ (CASTORIADIS, 1975). A plebe expõe um estado permanente de violência, de sofrimento e de injustiça produzindo imagens de desentendimento ${ }^{5}$, de intratável e uma igualdade que borra a ordem social estabelecida. Estas imagens são transmitidas a partir de um tipo singular de imaginários, que qualificaremos de "plebeus". Estes manifestam uma subjetivação política que nega a pretensão à totalidade de qualquer ordem política e, assim, referem-se à essência da política entendida como expressão da "diferença da sociedade em si mesma" (RANCIÈRE, 2004).

Como o escreveu Martin Breaugh (2007) em seu livro L'expérience plébéienne, a plebe é uma experiência política que corresponde a uma tradição desconhecida de afirmação da liberdade e da igualdade dos setores populares. Desconhecida, porque esta história é dupla e inclui sempre, de um lado, a narrativa dominante sobre o modo pelo qual as demandas populares foram representadas e "incluídas" na ordem política dominante e, por outro, a história subterrânea da rejeição radical das instituições políticas existentes por partes dos setores populares. Na sua vertente mais "disruptiva" do que "reformista", o impacto político dessa história é muitas vezes retraído. No entanto, ela compartilha uma experiência política revelando a falsa alegação ao "comum" de toda ordem política. É esta dupla história que designam, na Grécia Antiga, os termos "demos" e "boi polloi", os latins "populus" e "plebe" na República romana, ou "povo-nação" e "multidão" nas revoluções modernas. Frente ao demos, ao populus ou ao povo-nação, a plebe tem a particularidade de ficar de fora das instituições políticas e de qualquer espaço de fala comum.

Martin Breaugh lendo Foucault, Rancière e Ballanche, situa esta reflexão no cenário inaugural da primeira secessão plebeia em 494 a.C. Efetivamente, o termo de plebe refere-se primeiramente à Roma Antiga. É então plebeu quem não tem nome e não tem direito à fala pública. Segundo Breaugh, a primeira secessão plebeia inaugurou uma configuração política da qual é possível identificar traços em diferentes períodos da história

\footnotetext{
4 Tradução livre: "présuppose la capacité de voir dans une chose ce qu'elle n’est pas, de la voir autre qu'elle n'est".

5 O conceito usado por Jacques Rancière é o de "mésentente". Pode parecer traduzível por desentendimento mas de facto não é. Des-entendimento é um não-entendimento. Ora "mésentente" não é isso. Também não é o "mal entendido" que radica na imprecisão das palavras. segundo Ranciére, os casos de "mésentente" são aqueles nos quais a disputa sobre o sentido de "falar" constitui a própria racionalidade do acto da palavra, embora ela não se refira apenas a palavras mas mais sobre a situação daquele que fala, a qualidade (social) daquele que tem o direito à palavra.
} 
ocidental $^{6}$. A peculiaridade da plebe é, então, de ser muda e sem participação à vida política da cidade. Isto levanta um ódio intenso entre patrícios e plebeus e provoca a remoção da plebe no Aventino. Se este episódio é seguido por uma reintegração da plebe em Roma pela instituição dos tribunos plebeus que a representam, o que autoriza o conceito de plebe a uma renovação da análise política se localiza, porém, na experiência da "secessão" como "intervenção temporária no visível e enunciáveis" (FAYE, 1972), isto é: o que a ordem política estabelecida dá ou não dá para ver.

Esta intervenção no visível refere-se a uma definição ranciériana da política. Segundo Rancière, a política implica uma distribuição de lugares e funções no espaço social e necessariamente leva a um "equívoco" (mécompte) de certos grupos sociais que estão excluídos do poder coletivo. Neste sentido, a política inevitavelmente leva a um litígio sobre a existência de uma cena comum e sobre a qualidade dos sujeitos que estão presentes nela (RANCIÈRE, 1995). Na perspectiva de Rancière, o desentendimento plebeu é um litígio sobre a impossibilidade de um lugar comum onde a ordem política pode ouvir a palavra de sujeitos cuja particularidade é ser privado de discurso público (logos) e reduzido à simples expressão animal de prazer e dor (phonê).

Entendida como transgressão de uma ordem política, negando a certas categorias o status de sujeito político, essa postura da plebe é inseparável de uma "pressuposição da igualdade de qualquer ser falante com qualquer outro ser falante" (RANCIÈRE, 2004). Sua rejeição de distribuição hierárquica de lugares e funções desempenhadas pela ordem estabelecida procede de uma afirmação do estatuto de igualdade de todas as vítimas do equívoco na distribuição de lugares e funções pela ordem estabelecida. A substância da postura plebeia é a de uma desidentificação, "de um arrancamento à naturalidade de um lugar, a abertura de um espaço onde qualquer um pode ser contado, porque é o espaço do conto dos incontáveis ${ }^{7 "}$ (RANCIÈRE, 1995). No entanto, além de declarar o seu estado de ilegitimidade, a ordem estabelecida não consegue classificar de outra forma esse "excedente" composto pelo surgimento dos "sem-status".

Porém, a plebe não procura estabelecer uma legitimidade alternativa. Encontrando o seu lugar neste ilegítimo, a multidão continua intratável: ela se recusa a ser integrada na ordem política estabelecida. Como o escreve Breaugh, "o intratável na política aponta na

\footnotetext{
6 Por exemplo: a primeira secessão plebeia em 494 a.C., a revolta dos Ciompi em 1378, a revolta de Masaniello em 1647, os Sans-culottes da revolução francesa, os Jacobinos inglêses do século XVIII, os Communard de 1871, etc... Ver Breaugh (2007).

7 Tradução livre: "d'un arrachement à la naturalité d'une place, l'ouverture d'un espace de sujet où n'importe qui peut se compter parce qu'il est l'espace d'un compte des incomptés" (RANCIÈRE, 1995).
} 
direção do que não pode ser colocado em comum. O tratamento político envolve a criação de um comum ${ }^{8 "}$ (BREAUGH, 2007). Esta característica intratável e igualitária dos "semstatus" não se encontra tanto dentro de atores políticos determinados, ou em algum movimento social que ainda pode ser sujeito a regulamentação consensual e integrado dentro do sistema político vigente, mas sim no seio de imaginários plebeus como expressões das margens do social. Taxado como "ilegítimo", "violento" ou "delinquente" pela ordem estabelecida, a postura plebeia que resulta desses imaginários não é analisada aqui na busca de uma genealogia historicista de movimentos progressistas, mas de uma genealogia foucaultiana que permite a entrada na análise política de saberes assujeitados, ou seja, ilegítimos.

\section{O PCC E A REAPROPRIAÇÃO DE IMAGINÁRIOS PLEBEUS}

Este artigo se concentra sobre o escopo político da reapropriação de imaginários plebeus no seio de certos enunciados-chave que compõem o "PCC". Eles atravessam tanto a versão narrativa do nascimento do Partido como as recentes alterações ao seu lema ou as narrativas de presidiários e moradores de periferias. A presença desses imaginários plebeus participa da construção e disseminação de um "PCC-plebeu" nas margens do social como experiência política que transcende a figura alternativa de "PCC-crime organizado".

O lema do PCC era originalmente "paz, justiça, liberdade", ao qual a palavra "igualdade" foi adicionada em 2003, depois de uma séria sublevação dentro dos presídios paulistanos. De acordo com Dominique Maingueneau, os lemas podem ser interpretados como "frases sem texto" (MAINGUENEAU, 2012), ou seja, eles parecem significar por si só, sendo desjuntados de qualquer origem e da sua primeira situação de enunciação. Se o locutor imediato do lema é a organização representada por ele - neste caso, o PCC -, o lema político recebe uma segunda voz, associada a uma memória que mantém à risca dos usos anteriores das palavras que compõem-no, neste caso os termos de "paz, justiça, liberdade e igualdade." Através de um estudo da música popular de Jorge Ben e Tim Maia nos anos 1960 e 1970 e do rap nacional das décadas de 1990 e 2000, Gabriel de Santis Feltran (2013) mostra que valores políticos como paz, justiça, liberdade e igualdade não são nada recente nas margens do social. Esses valores foram presentes nas ações dos movimentos de trabalhadores da periferia (anos 1960-1970) e hoje na construção social do

\footnotetext{
8 Tradução livre: "l'intraitable en politique pointe vers ce qui ne saurait faire l'objet d'une mise en commun. Le traitement politique implique la création d'un commun" (BREAUGH, 2007).
} 
"crime" como guardião legitimado desses valores. A narrativa da fundação do PCC o situa numa memória das lutas contra a opressão dos marginalizados e "sem status". O PCC coloca em prática todo um repertório de imagens que o remete ao universo simbólico da luta dos oprimidos contra opressores e à uma narrativa social marcada pela injustiça, pela violência e pela miséria, cuja possibilidade de superação é dada pela união de todos os pobres.

Com efeito, a particularidade dos enunciados colocados em circulação pelo PCC é a extensão da opressão das categorias dos "bandidos" e "presidiários" para a categoria "dos muitos", isto é, dos "pobres" como comunidade de sem status. Como defendido por Breaugh, a experiência plebeia refere-se à imagem dos muitos, um princípio de "agorafilia" onde a política é instituída através e pela ação política da maioria (BREAUGH, 2007). No seu depoimento na Comissão de Combate à Violência, Marcola, indicado como chefe ${ }^{9}$ do PCC pela Segurança Pública, narra a criação do Partido da seguinte forma:

\begin{abstract}
"Não tenho [neste pavilhão de segurança máxima] direito a nada, e já não tinha em 1991, 1992 e 1993, quando foi fundado o PCC. Então, o PCC foi fundado por isso e por causa da chacina do Carandiru, onde foram assassinados 111 presos. Estou dentro de uma prisão onde morrem 111 presos. Eu me sinto inseguro, doutor. O PCC foi fundado porque não tinha para onde correr. Se a gente reclama, se a gente manda ofício, ninguém toma nenhuma atitude, ninguém olha para o preso, principalmente porque é pobre ${ }^{10 "}$.
\end{abstract}

Inserindo-se na gênese do evento hoje conhecido como o "massacre do Carandiru ${ }^{11 "}$, ocorrido no dia 12 de outubro de 1992, a narrativa do advento do PCC expõe a situação subumana de presos ("Ninguém olha para o preso") sem direitos. Este nexo de causalidade entre o massacre e o nascimento do PCC, além de estar presente nas narrativas de vários detentos, também foi enunciado em um comunicado de imprensa (salve) de 2006

\footnotetext{
${ }^{9}$ Como indicado previamente por Gabriel Feltran, a figura do líder no PCC lembra a autoridade do chefe nativo descrito por Clastres: ritualmente reconhecido, mas igualitária no que ela não pode determinar novas regras. Ver MARQUES (2010).

${ }^{10}$ Depoimento de Marcos William Herbas Camacho, o Marcola, à Comissão de Combate à Violência, da Câmara dos Deputados, prestado em 21/8/2001, resumido no relatório final da comissão, p. 126. Marcola é apontado como um dos principais líderes do PCC desde 2002, após o rompimento com os fundadores Geleião e Cesinha. Na ocasião dessa declaração, portanto, a referida cisão ainda não tinha ocorrido.

${ }^{11}$ Refere-se ao massacre de mais de 111 presidiários pela Polícia Militar de São Paulo durante um motim ocorido no dia 12 de outubro de 1992, na Casa de Detenção do Carandiru. Jornais da época publicaram uma série de amostragens que indicaram entre $29 \%$ e $44 \%$ a proporção dos moradores de São Paulo apoiando a ação da polícia no massacre. Vinte anos depois, esse apoio mantém-se inalterado, enquanto uma pesquisa realizada pelo Datafolha em 4 e 5 de Abril de 2013 indica que 36\% da população continua apoiando a ação da polícia no massacre. "Julgamento fazer Carandiru massacre", Datafolha, 4 e 5 de Abril de 2013, Disponível em: [http://media.folha.uol.com.br/datafolha/2013/05/02/julgamento massacre carandiru 07042013.pdf.]. $[09 / 03 / 2014]$
} 
emitido em nome do PCC (BIONDI, 2010). Este massacre surge após a "transição democrática" 12 como ato performativo de um "dano constitutivo" da sociedade brasileira: "raramente a justiça é feita, porque existem duas justiças também: a do pobre e a do rico ${ }^{13 " .}$ Ao inserir-se numa continuação lógica das repercussões desse dano constitutivo, o PCC se manifesta como afirmação política de um ator há muito excluído, submetido a um estado permanente de violência, sofrimento e injustiça.

Esta narrativa não só denuncia o status infrapolítico dos detentos, mas afirma que não é um status apenas característico dos bandidos, mas de um conjunto maior, o dos pobres. O conector "porque" estabelece um nexo de causalidade entre um fato consumado ("ninguém olha para o preso") e a inserção de um novo elemento cuja função é explicar este fato por referência à condição comum dos pobres ("principalmente porque é pobre"). Este enunciado afirma que o componente social rejeitado pela ordem política não é o "bandido", mas a "plebe" na qual o detento pertence. Esse status infrapolítico que afeta os detentos caracteriza a existência dos pobres, dos "muitos" que compartilham em comum a especificidade de não poder tomar a palavra e integrar uma deliberação pública. Tal como Rancière o afirma: "'os pobres' não designa a seção dos economicamente desfavorecidos da população, [mas] as pessoas que simplesmente não contam, aqueles que não têm maneira de exercer a força do arkhè, que não têm nenhum status a ser contado ${ }^{14 "}$ (RANCIÈRE, 2004).

$\mathrm{Na}$ ausência de fala pública, expressa-se uma igualdade entre os pobres ${ }^{15}$. Uma igualdade que caracteriza os imaginários plebeus e que, no caso do PCC, encontra a sua realização na adição do ideal de igualdade ao lema de "paz, justiça, liberdade". Após o seu nascimento, o PCC adota a forma de uma estrutura piramidal hierárquica, tendo no seu topo os dois principais membros fundadores: Cesinha e Geleião. Em seguida, conforme relatado por Marcola, "as pessoas ligadas a essa liderança se embriagaram com esse sucesso

${ }^{12}$ Esse acontecimento teve ampla repercussão internacional e chegou a colocar o país no banco dos réus na Corte Interamericana da Organização dos Estados Americanos.

13 Transcrição ipsis verbis da tomada de depoimento de Marcos Willians Herbas Camacho (Marcola) pela CPI (Comissão Parlamentar de Inquéritos) do Tráfico de Armas - realizada pelo Departamento de Taquigrafia, Revisão e Redação da Câmara dos Deputados -, que ocorreu durante a reunião fechada no 0871R/06, em 08/06/2006, com início às 13h30min e término às 17h43min, nas dependências da penitenciária de $\begin{array}{llllll}\text { Presidente } & \text { Bernardes } & \text { (SP), } & \text { p. } & 131 . & \text { Disponível }\end{array}$ [http://www1.folha.uol.com.br/folha/cotidiano/20060708-marcos camacho.pdf.][08/03/2014].

14 Tradução livre: " 'les pauvres' ne désigne pas la partie économiquement défavorisée de la population, [mais] simplement les gens qui ne comptent pas, ceux qui n’ont pas de titre à exercer la puissance de l'arkhèe, pas de titre à être comptés".

15 Dagnino et all. Cultura democrática e cidadania. Opinião Pública, Campinas: 1995, demonstraram como a noção de "democracia" entre os pobres não quer dizer eleições ou imprensa livres, nem poliarquia, mas tratamento igualitário nos cotidianos. 
todo [...] e acabaram cometendo atrocidades pior do que aquelas que eles vieram para coibir $^{16 "}$. Foi entre 2002 e 2003 que surge um violento conflito dentro do grupo ${ }^{17}$, inaugurando uma nova configuração de poder exigindo a igualdade entre todos e que se materializou pela adição da palavra "igualdade" ao lema do PCC (NUNES DIAS, 2011). Construiu-se uma organização de tipo celular, na qual, apesar de haver hierarquia, com uma cúpula ao centro, há vários níveis intermediários, que dividem o poder. Surge um novo discurso de democratização que nega a existência de lideranças, ressaltando o caráter coletivo das decisões tomadas. Sendo contrária ao princípio da igualdade, a figura do líder ou do chefe é então estigmatizada : "Esse ideal de igualdade pressupõe liderança legítima, mas sem mando, calcada em autoridade reconhecida e ritualmente confirmada no modo de performar suas relações, tanto cotidianas quanto no 'mundo do crime', mediando ou resolvendo conflitos" (FELTRAN, 2013). Dentro e fora das prisões, Feltran nota que "no ideal compartilhado pelos "irmãos", a virtude aparece, portanto, exatamente na atitude de se colocar como igual a todos os seus pares" (FELTRAN, 2013). Nossa proposta aqui não destina-se a saber se o modo de funcionamento real do PCC é conforme ao ideal igualitário, mas sim de traçar os seus efeitos ao nível dos tipos de imaginários políticos reativados pelo discurso do PCC.

O PCC é caracterizado pela criação de uma linguagem vernácula que dá conta de um ideal igualitário, dirigido pela remoção de hierarquias e uma preocupação para a prática diária da igualdade e da multiplicidade. Ao invés de falar de ordens, os participantes do PCC instituem o termo de salve. " Em todos seus usos, o salve não carrega peso hieráriquico nenhum. "[...] seu conteúdo é fundamentalmente distinto de termos como lei, ordem, regra ou decreto" (BIONDI, 2010). Ao tomar certas decisões importantes, são implementados debates onde cada um expõe o seu ponto de vista em busca de um consenso. A posição política de Piloto substituiu o termo de voz por considerá-lo uma forma de supressão de uma multiplicidade. Conforme expresso por um detento entrevistado por Biondi, "É que não dá pra falar de uma voz só...Olha quanto preso tem nesse xis [cela]!" (BIONDI, 2010). Como demonstrado por Karina Biondi (2010), em seu livro Junto e Misturado, se há uma hierarquia dentro do PCC, existe também um esforço dos presos no sentido de tentar forças igualitárias no âmbito linguístico. Esse ideal de igualdade que atravessa o PCC está

16 Depoimento de Marcos Willians Herbas Camacho (Marcola) pela CPI (Comissão Parlamentar de Inquéritos) do Tráfico de Armas, op. cit., p. 69-70.

${ }^{17}$ Cesinha foi assassinado na Penitenciária de Avaré, em 13 de agosto de 2006. Geleião permanece em uma unidade prisional de seguro desde então. 
localizado no coração de imaginários plebeus centrados na igualdade dos "sem status". Como afirmado por Oskar Negt, a carga revolucionária dos movimentos populares "vem principalmente a partir de uma atuação prática e viva da lembrança de igualdade e da autorregulação democrática originária ${ }^{18 "}$ (NEGT, 2007).

Como observa Catherine Huart, a plebe exibe uma recusa de tratamento a partir da sua relação ambígua com a figura do "chefe", muitas vezes ligada à figura do traidor nos imaginários plebeus (HUART, 2012). O PCC continua intratável. Esta recusa de tratamento está indicado pelo intervalo criado entre a interpretação dominante de um "PCC-crime organizado" e a de um "PCC-plebeu". O "tratamento" pressupõe um espaço de fala comum entre a "plebe" e a ordem política. Como vimos acima, é a ausência deste espaço comum que denuncia a narrativa sobre a fundação do PCC. O tratamento requer o estabelecimento de uma organização, formada por representantes que interagem com as autoridades. Fora dos canais institucionais, as ações da plebe podem, portanto, revelar os aspectos "expressivos-disruptivos" da ação política (deslocamento da ordem dominante) ao invés de um aspecto exclusivamente instrumental (repertórios de ações coletivas) $\left(\right.$ DOIMO, 1995) ${ }^{19}$. Em qualquer revolta, há um aspecto corporativo ou instrumental: queremos obter algo considerado como historicamente legítimo. Pelo seu aspecto expressivo, o movimento de revolta supera totalmente a sua significação instrumental. Ele indica o componente da ação por meio da qual se manifestam valores morais ou apelos ético-políticos tendentes a deslegitimar a autoridade pública e afirmar identidades. Se o "PCC-crime organizado", de fato, apresenta uma série de demandas dirigidas às autoridades (ALVAREZ, SALLA e NUNES DIAS, 2013), ele é imediatamente dominado pelo seu caráter de intratabilidade. Como observou o ex-secretário da Secretaria da Administração Penitenciária (SAP): "em meados de 2005, começaram sistematicamente a acontecer rebeliões, com características de destruição, sem reivindicação nenhuma" (FUKURAWA, 2008). Adalton Marques enfatiza que uma das principais "propostas políticas" do PCC pode ser enunciada pela proposta "quebrar cadeia" : "Ao contrário de significar um mero procedimento de vandalismo, esta tática consiste em manter um estado permanente de tentativas de fuga" (MARQUES, 2007). A ausência de demandas concretas decorre menos de uma "deficiência" do que uma "recusa": uma "recusa de tratamento", uma recusa do lugar atribuído à plebe na ordem policiada.

\footnotetext{
18 Tradução livre: "provient surtout d'une mise en pratique vivante du souvenir de l'égalité et de l'autorégulation démocratique originelles ".

${ }^{19}$ Ver a aplicação desta distinção em DÉCARY-SECOURS e FAUSTINO DA COSTA (2012).
} 


\section{O IDEAL DA "PAZ" E O DOMÍNIO DO UM: A DISCIPLINA DO COMANDO}

Expondo a negação da capacidade de fala pública do pobre pela ordem política estabelecida, como também o caráter espúrio da unidade e harmonia de projetos sociais que aspiram à integração social, os imaginários plebeus não propõem o estabelecimento de um nova ordem democrática. No máximo, o valor político destes é de interromper o curso normal da reprodução social, revelando uma nova "realidade", em que os "deixados para trás" exigem serem contados (RANCIÈRE, 1995). Atravessado por esses imaginários de emancipação, igualidade e liberdade, o "PCC-plebeu" não está por isso ao abrigo da heteronomia, da dominação e de uma nova ordem de pretensão totalitária. A servidão, escreve Breaugh, leitor de La Boétie, "não se deve ao medo da morte ou até mesmo do hábito. Ela se deve em vez à um encantamento, um feitiço desencadeado pelo único nome de $\mathrm{Um}^{20 "}$ (BREAUGH, 2007). Conforme a análise de Nunes Dias sobre o PCC, "a concepção segundo a qual o chefe não deve se submeter a ninguém, é substituída pela idéia segundo a qual o Comando está acima de todos e a ele todos devem se submeter, inclusive as lideranças" (NUNES DIAS, 2011a).

O Primeiro Comando da Capital dá origem a esta nova unidade narrativa, instituindo uma Disciplina. Em tensão com os imaginários plebeus que revelam a diferença da sociedade em si mesma, o conceito do Um revela uma tendência oposta que surge com o objetivo de acabar com a indeterminação que caracteriza a "liberdade" e a convivência democrática (LEFORT, 1976). Trata-se da afirmação da totalidade, o reino da indivisão e o perecimento da liberdade de exercício de uma interrogação contínua da Lei. A Disciplina do Comando condensa essa vontade de acabar com a indeterminação, impondo uma série de "regras" ou normas dentro das prisões e periferias de São Paulo, garantindo a "paz" contida em seu lema.

A criação do PCC é realmente vivenciada por muitos como o fim da violência endêmica, tanto dentro da prisão (BIONDI, 2010) quanto nos bairros periféricos (FELTRAN, 2013; 2010). Se a década de 2000 corresponde à institucionalização do PCC, com um declínio geral nas taxas de homicídio, ainda assim, esta "pacificação" conta com a ameaça permanente de violência. A não observância desta Disciplina leva a uma série de

\footnotetext{
20 Tradução livre: "La servitude, écrit Breaugh lecteur de La Boétie, ne tient pas à la peur de la mort ni même
} de l'habitude. Elle tient plutôt à un enchantement, un ensorcellement suscité par le seul nom d’Un". 
sanções, incluindo a pena de morte. Segundo Biondi (2010), o PCC adquiriu uma transcendência que o coloca acima dos indivíduos que o compõem e, por conta disso, as vontades pessoais dos seus integrantes não podem ser reveladas, assim como a Disciplina é vista como tendo uma existência autônoma, independente deles. Esta naturalização de uma série de regras heterônomas postula a existência de um princípio motor que nada precede. Como observado por Biondi (2010) e Nunes Dias (2013), o termo "punição" nao faz parte da gramática dos participantes do PCC. As sanções para o descumprimento da Disciplina não são enunciadas como punições, cuja origem é a de uma lei, de uma ordem instituída pelo homem, mas como consequência ou cobrança da transgressão de uma ordem natural. De acordo com o enunciado "nada é proibido, mas tudo vai ter uma consequência", recolhido por Biondi em seu estudo etnográfico nas prisões paulistas, encontra-se o esboço de uma ordem natural sem origem precisa (transcendente) que pretende ser totalmente compatível com os ideais de "liberdade" e "igualdade". O estabelecimento de uma ordem política "natural" é motivada pelo desejo de unidade do corpo político que reintegra os prisioneiros, os "pobres" ou os "sem status" na mesma dinâmica de violência subjacente ao desejo de emancipação contido nos imaginários plebeus.

\section{CONSIDERAÇÕES FINAIS}

As teorias sobre a experiência plebeia são parte de um contexto intelectual singular na França, marcado na véspera dos anos 2000 por uma renovação das reflexões políticas sobre a democracia contemporânea (LABELLE e TANGUAY, 2003). Elas fazem parte de uma concepção substancial de democracia, da ação "dos muitos”, e de um retorno às origens da democracia ateniense instituída como a "capacidade de fazer coisas" (JOSIAH, 2008), cuja expressão formal é o princípio da isonomia, entendida como a igual participação dos cidadãos na criação da lei. Este princípio político expresso pelos "muitos" nem sempre toma a forma de um movimento político racional e organizado, mas no entanto é reativado nas margens do social como expressão política dos "deixado para trás", dos sem vozes. O conceito de imaginários plebeus tem como objetivo permitir a entrada na análise política de experiências e saberes assujeitados, ou seja, ilegítimos e criminalizados.

No contexto do retorno à norma democrática no Brasil, a violência está agora reduzida ao seu componente exclusivamente criminal. Por sua vez, esta é reduzida a uma questão de Segurança Pública, de crime organizado e à ativação do PCC. Se o paradoxo colocado pela coexistência do projeto democrático e do surgimento da violência criminal 
tem produzido várias pesquisas acadêmicas, o vínculo entre política e violência criminal ainda precisa ser esclarecido. A experiência plebeia não é uma teoria de auto-emancipação, nem uma legitimação de práticas criminais. A questão investigada nesse texto é diferente: o que acontece com o projeito democrático quando o desejo de emancipação, liberdade e igualdade dos setores populares encontra sua ressonância no seio de imaginários que são reativados por grupos criminais e se difundem para além dos limites físicos deste grupo? A problemática que atualmente oculta a análise política da violência no Brasil está em um emaranhado, cuja escala é sem precedentes, entre os espaços sociais pauperizados e criminalizados. O conceito de imaginários plebeus tem como objetivo identificar a passagem de uma problematização da violência que se coloca em termos de "criminalização da luta política" sob a ditadura militar, à sua problematização em termos de "politização e propagação dos imaginários criminais" no contexto "democrático".

\section{REFERÊNCIAS BIBLIOGRÁFICAS}

ADORNO, S. e SALLA, F. 2007. Criminalidade organizada nas prisões e os ataques do PCC, Estudos Avançados. Dossiê Crime Organizado. São Paulo, v. 21, n. 61, p. 7-29.

ALVAREZ, M. C., SALLA, F. e NUNES DIAS, C. 2013. Das Comissões de Solidariedade ao Primeiro Comando da Capital em São Paulo, Tempo Social, v. 25, n. 1, 2013, p. 61-82.

ANISTIA INTERNACIONAL. 2011. A situação dos direitos bumanos no Brasil, Disponível em: [http://www.amnesty.org/fr/node/25117]. [09/03/2014],

BARROS, J. de. 2006. A construção do PCC, Caros Amigos, São Paulo, edição extra, ano X, n. 28 , p. 3-13.

BIONDI, K. 2010. Junto e misturado: uma etnografia do PCC. São Paulo: Terceiro Nome/Fapesp.

BOSI, A (ed.). 2007. Dossiê crime organizado, Estudos Avançados, São Paulo: Instuto de Estudos Avançados da USP, v. 21, n. 61.

BREAUGH, M. 2007. L'expérience plébéienne. Une histoire discontinue de la liberté politique. Paris: Payot.

CALDEIRA, T. 2000. City of Walls: Crime, Segregation and Citizenship in São Paulo, Berkeley: University of California Press.

1996. Crime and Individual Rights : Reframing the Question of Violence in Latin America, In : JELIN Elizabeth e Eric HERSHBERG (eds), Constructing Democracy: Human Rights, Citizenship and Society in Latin America, Boulder: Westview. 
CASTORIADIS, C. 1975. L'institution imaginaire de la société, Paris: Éditions du Seuil.

CORTEN, A., PENAFIEL, R. et HUART, C. (eds). 2012. L'interpellation plébéienne en Amérique latine, Paris/Montréal, Karthala/Presses de l'université du Québec.

DÉCARY-SECOURS, B. e FAUSTINO DA COSTA T. 2012. Le versant expressif des actions directes de la plèbe au Brésil. Le Mouvement des travailleurs ruraux sans-terre (MST), In : L'interpellation plébéienne, CORTEN, A., PENAFIEL, R. e HUART C. (eds), Paris/Montréal, Karthala/Presses de l'université du Québec.

DAGNINO, E. 1995. Cultura democrática e cidadania. Campinas : Opinião Pública.

DOIMO, Ana Maria. 1995. A Vež e a Voz. do Popular, Rio de Janeiro : RelumeDumará.

FELTRAN, G. De S. 2013. Sobre anjos e irmãos: cinquenta anos de expressão política "crime" numa tradição musical das periferias. Revista do Instituto de Estudos Brasileiros, n. 56.

2010. Crime e castigo na cidade: os repertórios da justiça e a questão do homicídio nas periferias de São Paulo", Caderno CRH, Salvador, v. 23, n. 58.

2008. Fronteiras de tensão: um estudo sobre política e violência nas periferias de São Paulo. Campinas, tese de doutorado, Programa de Pós-Graduação em Ciências Sociais da Unicamp.

FAYE, J. 1972. Théorie du récit. Introduction aux «langages totalitaires». La raison critique de l'économie narrative, Paris: Hermann.

GODÓI, R. 2010. Ao redor e através da prisão: cartografias do dispositivo carcerário contemporâneo. São Paulo, dissertação de mestrado em sociologia, Faculdade de Filosofia, Letras e Ciências Humanas da Universidade de São Paulo.

KRUIJT, D. e KOONINGS, K. 1999. Introduction: Violence and Fear in Latin America in : KRUIJT, D. e KOONINGS, K. (eds), Societies of Fear: The Legacy of Civil War, Violence and Terror in Latin America, Londres: Zed books.

FUKURAWA, N. 2008. Entrevista. Novos Estudos Cebrap, São Paulo, n. 80.

HUART, C. 2012. L'irreprésentable plèbe. Le cas des batailles de l'Assemblée populaire des peuples d'Oaxaca (Mexique), In : CORTEN, A., PENAFIEL R. et HUART C. (eds), L'interpellation plébéienne en Amérique latine. Paris/Montréal : Karthala/Presses de l'université du Québec.

JOSIAH, O. 2008. The Original Meaning of "Democracy". Capacity to Do Things, not Majority Rule, Constellations, v. 15, n. 1.

LABELLE, G. e TANGUAY, G. 2003. Le retour de la philosophie politique en France, Politique et Sociétés, v. 22, n. 3.

LEFORT, C.. 1976. Le nom d’Un In: Étienne de La Boétie, Le Discours de la servitude volontaire, Paris: Payot. 
1972. Le travail de l'oeuvre Machiavel, Paris: Gallimard.

MAINGUENEAU, D. 2012. Les phrases sans texte, Paris: Armand Colin.

MANSO, B. 2009. Um debate sobre o PCC : Entrevista com DIAS, C. N., FELTRAN G. de S., MARQUES, A. e BIONDI, K., Revista de Antropologia Social dos Alunos do PPGASUFSCar, v. 1, n. 2.

MARQUES, A. J. 2010. "Liderança", "proceder" e "igualdade": uma etnografia das relações políticas no Primeiro Comando da Capital, Etnográfica, v. 14, n. 2.

2009. Crime, proceder, convivio-seguro: um experimento antropológico a partir de relações entre ladrões. São Paulo, dissertação de mestrado em antropologia social, Faculdade de Filosofia, Letras e Ciências Humanas da Universidade de São Paulo.

2007. "Faxina" e "pilotagem": dispositivos (de guerra) políticos no seio da administração prisional, Lugar Comum, n. 25-26.

COMISSÃO DE COMBATE A VIOLENCIA, Depoimento de Marcos William Herbas Camacho, Câmara dos Deputados, prestado em 21/8/2001.

MINGARDI, G. 2007. O trabalho da inteligência no controle do Crime Organizado, Estudos Avançados, v. 21, n. 61.

NEGT, O. 2007 L’Espace oppositionnel, Paris :Payot. FALTA COISA

NUNES DIAS, C. C. 2013. PCC - Hegemonia Nas Prisões e Monopólio da Violência, São Paulo: Saraiva.

2011a. Da pulverizaçãa ao monopólio da violência: expansão e consolidação do Primeiro Comando da Capital (PCC) no sistema carcerário paulista, Tese de doutorado, Departamento de Sociologia da Faculdade de Filosofia, Letras e Ciências Humanas da Universidade de São Paulo.

Social, v. 23 , n. 2.

2011b. Estado e PCC em meio as tramas do poder arbitrario na prisao, Tempo

PERALVA, A. 2001. Violence et démocratie. Le paradoxe brésilien, Paris: Balland.

RANCIÈRE, J. 2004. Aux bords du politique, Paris: Gallimard.

1995. La mésentente politique et philosophique, Paris: Galilée.

SOUZA, F. 2007. PCC, a facção, Rio de Janeiro: Record.

TEIXEIRA, A. 2012. Construir a delinquência, articular a criminalidade: um estudo sobre a gestão dos ilegalismos na cidade de São Paulo. São Paulo, tese de doutorado em sociologia, Faculdade de Filosofia, Letras e Ciências Humanas da Universidade de São Paulo. 
Juruá.

2009. Prisões da exceção: política penal e penitenciária no Brasil contemporâneo. Curitiba:

ZALUAR, A. 2007. Democratizaçao inacabada: fracasso da segurança pública, Estudos Avançados, v. 21, n. 61. 